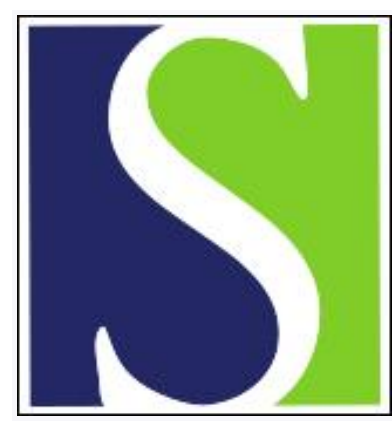

Scand J Work Environ Health 2000;26(5):414-420

https://doi.org/10.5271/sjweh.562

Issue date: Oct 2000

\title{
Standing at work and varicose veins
}

by Tüchsen F, Krause N, Hannerz H, Burr H, Kristensen TS

The following article refers to this text: 2003;29(4):270-279

Key terms: epidemiology; hospitalization; prospective study; record linkage; varicosis; venous insufficiency

This article in PubMed: www.ncbi.nlm.nih.gov/pubmed/11103840

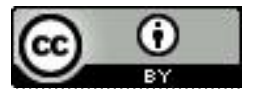




\title{
Standing at work and varicose veins
}

\author{
by Finn Tüchsen, MSc, ${ }^{1}$ Niklas Krause, MD, ${ }^{2,}{ }^{3}$ Harald Hannerz, BSc, ${ }^{+}$Hermann Burr, PhD, ${ }^{1}$ \\ Tage S Kristensen, DrMedSci'
}

\author{
Tüchsen F, Krause N, Hannerz H, Burr H, Kristensen TS. Standing at work and varicose veins. Scand J Work \\ Environ Health 2000;26(5):414-420.
}

\begin{abstract}
Objectives This study attempts to determine whether or not prolonged standing at work involves an excess risk for the occurrence of varicose veins.

Methods A cohort of 1.6 million 20-to-59-year-old Danes gainfully employed in 1991 were followed for 3 years according to first hospitalization due to varicose veins of the lower extremities. The exposure data came from a representative sample of the baseline population. Altogether 5940 people were interviewed about occupational exposure and confounding factors.

Results For men working mostly in a standing position, the risk ratio for varicose veins was 1.85 [95\% confidence interval (95\% CI) $1.33-2.36$ in a comparison with all other men. The corresponding risk ratio for women was 2.63 (95\% CI 2.25-3.02). The results were adjusted for age, social group, and smoking.

Conclusions Working in a standing position is associated with subsequent hospitalization due to varicose veins for both men and women.
\end{abstract}

Key terms epidemiology, hospitalization, record linkage, prospective study, varicosis, venous insufficiency.

Varicose veins of the lower extremities is 1 of the 10 leading reasons for hospitalization in Denmark (1). In fact, the most common in-hospital vascular disorder among women is acute venous thrombosis of the minor and major deep veins of the leg. In population studies the prevalence of visible tortuous varicose veins has been reported to be $10-15 \%$ for men and $20-25 \%$ for women (2-4). In a recent cross-sectional study in Edinburgh the age-adjusted prevalence of varicose veins was $58 \%$ for men and $48 \%$ for women (5).

Varicose veins are dilated, tortuous superficial veins with incompetent valves. Primary varicose veins occur in the absence of deep venous disease and generally have a benign course, although the acute obstruction and inflammation of the superficial veins (acute thrombophlebitis) can be a rather painful and dramatic event. Varicosities that occur secondary to obstruction and valvular incompetence of the deep venous system are much more serious and potentially lethal because of the associated risk of pulmonary thromboembolism. The loss of the valvular mechanism in the deep venous system forces the blood to follow abnormal pathways, particularly during standing and exercise. In the standing position or during walking the muscle pump pushes blood proximally, distally, and out through the perforating veins into the superficial system. By increasing venous and capillary pressures, this sequence of events, over a period of many years, leads to chronic edema, repeated inflamation, and, finally, to the postphlebitic syndrome including stasis ulcers that are difficult to manage and often disabling. The etiology of venous vascular diseases has not been studied systematically, but several clinical and occupational risk factors have been proposed in the literature.

Higher risks for varicose veins have been associated with obesity, high systolic blood pressure, cigarette smoking, and low levels of physical activity (6).

Unfortunately, there is no systematic literature review regarding occupational risk factors for varicose veins. Two recent narrative reviews on risk factors for varicose veins, although published at the same time, differ regarding the cited literature $(2,7)$. Both reviews conclude that the evidence for occupational risk factors, including prolonged standing, for varicose veins is equivocal. However, the reviews neither searched the available literature

1 National Institute of Occupational Health, Copenhagen, Denmark.

2 School of Public Health, University of California, Berkeley, California, United States.

3 Division of Occupational and Environmental Medicine, University of California, San Francisco, California, United States.

Reprint requests to: Mr Finn Tüchsen, Department of Surveillance and Epidemiology, National Institute of Occupational Health, Lersø Parkallé 105, DK-2100 Copenhagen Ø, Denmark. [E-mail: ft@ami.dk] 
systematically nor evaluated the methodological quality of the reviewed studies. Most studies are cross-sectional, have no adequate exposure measurement, and do not control for confounders (8). Occupations associated with varicose veins are textile workers (9) and department store employees (10). One study reported that varicose veins were associated with heavy lifting but not with standing work postures (9). Seven studies suggest that prolonged standing at work is associated with venous diseases $(3,6,11-13)$. Two studies did not find an association between varicose veins and occupational factors (14-15). Two other higher quality population-based studies showed a significant association between work posture and varicose veins $(3,6)$. One, the Mini Finland Health Survey, reported a higher prevalence of varicose veins for men mainly standing at work, a finding which became significant only after adjustment for age and several other variables. However, prolonged standing often precipitates the symptomatology of varicose veins (heaviness and swelling). Therefore the temporal relationship between standing and varicose veins, and thus the causality, remain ambiguous in cross-sectional studies. Prospective studies are necessary to test the possibility of a causal relationship between prolonged standing and varicose veins. So far, only 1 prospective study, the population-based Framingham study, has addressed occupational factors. It found that women who reported spending $\geq 8$ hours a day in sedentary activities had a significantly higher incidence of varicose veins than those who spent $\leq 4$ hours a day in such activities (6). The Framingham study did not, however, address standing per se.

This new prospective study with a 3-year follow-up of the Danish population hypothesized that working in a standing position or walking results in higher hospitalization rates due to varicose veins.

\section{Subjects and methods}

\section{Study population}

The Occupational Hospitalization Register was used to calculate occupational age-standardized hospitalization ratios (SHR) in 1991-1993 against certain job group characteristics obtained from a representative random sample of the baseline population. The register is a research register with individual-level data on occupations, hospitalizations, and deaths in various cohorts and follow-up periods. All men and women in Denmark aged 20-59 years in January 1991 are included and classified according to their most important occupation in 1990. The information has been recorded by linkage of the population census of Denmark to the National In-patient Register, the Death Register, and the Employment Classification Module. The Employment Classification Module contains yearly information on economic activity, occupational classification, and industry. The occupational code is an extended classification of the International Standard Classification of Occupation, 1968 version, which also includes self-employed persons. The industrial code is a national extension of the International Standard Classification of all Economic Activity, 1968 version. The National In-patient Register provides information on more than $99 \%$ of all admissions to Danish hospitals, and it is updated every year. The personal identification number from the National In-patient Register was used in the cross-linking procedure and for information on gender, date, and year of birth.

Exposure information for occupational groups from the database of the Occupational Hospitalization Register was obtained through a representative random sample from the Central Population Register of Denmark in 1990, which contained 9653 adults in the age range of 18-59 years. Of these, 8664 agreed to be interviewed by telephone (response $90 \%$ ), and 5940 of the respondents were employees or had been so during the last 2 months before the interview (16). A series of questions about physical and psychosocial work environment, work processes, and life-style was asked. The sample, which we call the Danish work environment cohort study, includes 1 out of every 400 persons in the Occupational Hospitalization Register.

\section{Validity of the basic information}

Age and gender are a part of the personal identification number, and they are recorded practically without error. Their completeness and accuracy are shown by the fact that the matching of various registers according to the personal identification number was $100 \%$ complete. Misclassifications of occupation are negligible among employees in the public sector, who total approximately one-third of the male and half of the female work force. In the private sector the primary data producers do not routinely check data on occupation, but the Employment Classification Module contains information from various additional sources, and these additions help increase the validity of the data. For example, a recent thesis showed that $66 \%$ of the bus drivers occupied in the greater $\mathrm{Co}-$ penhagen area for more than 6 months in 1980, according to company personnel files, were also classified as bus drivers employed by a bus company. An additional $30 \%$ had 1 piece of the information correct. It was shown that this misclassification tends to bias the risk estimate slightly towards unity (17).

\section{Analysis}

The data were analyzed in 3 steps. In the 1st step we plotted standardized hospitalization ratios for varicose veins against occupational groups stratified according to the prevalence of smokers and the prevalence of people with work that requires prolonged standing. The purpose of 
this step was to create a visual description of the association between standing at work and varicose veins and to check for inconsistencies between the strata. In the 2nd step we used the Poisson regression to investigate the association between standing at work and varicose veins with simultaneous adjustment for social group and smoking habits. These steps would provide measures of relative morbidity between occupational groups with a high prevalence of exposed persons and those with a low prevalence of exposed persons. They would not, however, provide estimates of risk ratios between the exposed and unexposed persons. In the 3rd step we used elementary algebra to extract the individual-level risk ratio from the estimates provided in the 2 nd step of the analysis.

\section{Exposure definition}

Two group-level variables, smoking and standing at work, were formed for use in the Danish work environment cohort study. The smoking variable was defined in the following way: (i) the current and the former smokers were all classified as "smokers", (ii) the proportion of smokers in each occupation was calculated, (iii) the occupations were ranked according to smoking prevalence ( $1=$ lowest), (iv) the occupations in the first quartile with respect to the ranking were classified as having

Table 1. Number of occupations and respondents in the Danish work environment cohort study, persons at risk, cases of varicose veins in the study base, and hospitalization rate by gender, proportion of smokers and proportion of standing at work.

\begin{tabular}{|c|c|c|c|c|c|c|}
\hline \multirow[t]{2}{*}{ Gender } & \multicolumn{4}{|c|}{$\begin{array}{l}\text { Danish work environment } \\
\text { cohort study }\end{array}$} & \multicolumn{2}{|c|}{$\begin{array}{l}\text { Occupational } \\
\text { hospitalization } \\
\text { register }\end{array}$} \\
\hline & $\begin{array}{l}\text { Propor- } \\
\text { tion of } \\
\text { smokers }\end{array}$ & $\begin{array}{l}\text { Proportion } \\
\text { standing } \\
\text { at work }\end{array}$ & $\begin{array}{l}\text { Occupa- } \\
\text { tions } \\
(\mathrm{N})\end{array}$ & $\begin{array}{l}\text { Respon- } \\
\text { dents } \\
\text { (N) }\end{array}$ & $\begin{array}{l}\text { Persons } \\
\text { at risk } \\
\text { (N) }\end{array}$ & $\begin{array}{l}\text { Cases of } \\
\text { varicose } \\
\text { veins }(\mathrm{N})\end{array}$ \\
\hline \multicolumn{7}{|l|}{ Men } \\
\hline & \multicolumn{6}{|l|}{ Low } \\
\hline & & Low & 5 & 179 & 65409 & 69 \\
\hline & & Medium & 5 & 186 & 70964 & 122 \\
\hline & & High & 1 & 54 & 19762 & 58 \\
\hline & \multicolumn{6}{|c|}{ Medium } \\
\hline & & Low & 4 & 419 & 81783 & 132 \\
\hline & & $\begin{array}{l}\text { Medium } \\
\text { High }\end{array}$ & $\begin{array}{r}13 \\
4\end{array}$ & $\begin{array}{l}600 \\
186\end{array}$ & $\begin{array}{r}204614 \\
86817\end{array}$ & $\begin{array}{l}419 \\
204\end{array}$ \\
\hline & \multicolumn{6}{|l|}{ High } \\
\hline & & Low & 3 & 252 & 105224 & 189 \\
\hline & & Medium & 5 & 242 & 64660 & 150 \\
\hline & & High & 4 & 89 & 27912 & 82 \\
\hline \multirow{2}{*}{\multicolumn{7}{|c|}{ Women }} \\
\hline & & & & & & \\
\hline & & Low & 2 & 114 & 28706 & 55 \\
\hline & & Medium & 4 & 81 & 30431 & 105 \\
\hline & \multicolumn{2}{|c|}{ Medium } & & 41 & 1632 & 9 \\
\hline & & Low & 5 & 563 & 259611 & 603 \\
\hline & & Medium & 8 & 713 & 280926 & 1208 \\
\hline & & High & 4 & 291 & 141557 & 953 \\
\hline & mign & Low & 1 & 22 & 416 & 1 \\
\hline & & Medium & 6 & 194 & 55814 & 233 \\
\hline & & High & 2 & 324 & 80293 & 496 \\
\hline
\end{tabular}

a "low proportion of smokers", (v) occupations in the 4th quartile were classified as having a "high proportion of smokers", and (vi) the remaining job groups were classified as having a "medium proportion of smokers".

The occupational standing variable was formed in the same manner as the smoking variable. Occupations were classified as having a "low proportion of standing" if they were in the 1st quartile with respect to the proportion of employees with work that required them to stand or walk more than $75 \%$ of their workshift. Occupations in the 2 nd and 3rd quartile were classified as having a "medium proportion of standing". Occupations in the 4th quartile were classified as having a "high proportion of standing".

To obtain a reasonable precision in the estimated proportions, we excluded occupations with less than 15 respondents in the Danish work environment cohort study. Altogether, 44 male occupations and 33 female occupations were large enough to be included in the analyses. The proportion of smokers in the examined occupational groups varied between $31 \%$ and $88 \%$ (1st quartile $\leq 61 \%$ smokers, 4 th quartile $>75 \%$ smokers) among the men and between $44 \%$ and $83 \%$ (1st quartile $\leq 53 \%$ smokers, 4 th quartile $>68 \%$ smokers) among the women. The proportion of people standing more than $75 \%$ of their workshift varied between $0 \%$ and $100 \%$ (1st quartile $\leq 31 \%$, 4th quartile $>90 \%$ ) among the men and between $0 \%$ and $99 \%$ (1st quartile $\leq 9 \%$, 4th quartile $>73 \%$ ) among the women. The distribution of occupations and persons with respect to the "smoking" and "standing" variables is given in table 1 .

\section{Outcome definition}

All gainfully employed people in Denmark belonging to any of the selected occupations were followed from 1991 to 1993 for first hospital admission with varicose veins in the lower extremities [ 454 code of the International Classification of Diseases, 8th revision (ICD-8] as the principal discharge diagnosis. Altogether $727145 \mathrm{men}$ and 878756 women were included in the follow-up.

\section{Steps 1 and 2 - a group-level analysis}

Standardized hospitalization ratios (SHR), by occupational group and gender, were calculated by dividing the observed number of hospitalizations by the expected number. The expected number was based on corresponding gender and 5-year age-specific incidence rates for all gainfully employed persons in Denmark. The cohort members were no longer at risk of being admitted to a hospital in Denmark (censored) from the date of first emigration or from date of death, whichever came first.

Since the employment groups were large in relation to the number of cases, it was appropriate to model the standardized hospitalization ratio by a log-linear Poisson 
regression with the expected number of discharges as an offset. We performed an occupational-level multiple regression with the proportion of smokers (low, medium, high), the proportion of people in a prolonged standing position (low, medium, high), and the social group (senior salaried staff, leading salaried staff, other salaried staff, skilled workers, and unskilled workers) (18) as the explanatory indicator variables. We estimated the parameters using SAS (statistical analysis system of the SAS Institute, Inc) Proc Genmod, and we calculated the large-sample $95 \%$ confidence intervals (95\% CI) using the estimated standard errors.

\section{Step 3-extraction of individual-level estimates}

The preceding steps provided a pattern for the standardized hospitalization ratios and told us whether or not the proportion of exposed people in the various job groups was associated with the studied morbidity. They did not, however, furnish estimates of the relative risks between the exposed and unexposed persons. Since the employment groups with a high proportion of exposed persons also contained a certain proportion of unexposed people and vice versa, the effect of standing at work was underestimated in step 2.

Bias toward unity depends on the proportions in question. If, for example, the true risk ratio is 2.0 and $70 \%$ of the people in group A are exposed while only $20 \%$ are exposed in group $\mathrm{B}$, then the group-level risk ratio (RR) between group $\mathrm{A}$ and $\mathrm{B}$ would be reduced to $(0.7 \times 2+0.3 \times 1) /(0.2 \times 2+0.8 \times 1) \approx 1.4$.

In general terms, if $R_{\mathrm{G}}$ is the group-level $R R, R_{1}$ is the individual-level $R R, P_{A}$ is the proportion of exposed persons in group $A$, and $P_{B}$ is the proportion of exposed persons in group $\mathrm{B}$, then

$$
\mathrm{RR}_{\mathrm{G}}=\left[\mathrm{P}_{\mathrm{A}} \mathrm{RR}_{\mathrm{I}}+\left(1-\mathrm{P}_{\mathrm{A}}\right)\right] /\left[\mathrm{P}_{\mathrm{B}} \mathrm{RR}_{\mathrm{I}}+\left(1-\mathrm{P}_{\mathrm{B}}\right)\right]
$$

which is equivalent to

$$
\mathrm{RR}_{\mathrm{L}}=\left[\mathrm{RR}_{\mathrm{G}}\left(1-\mathrm{P}_{\mathrm{B}}\right)+\mathrm{P}_{\mathrm{A}}-1\right] /\left[\mathrm{P}_{\mathrm{A}}-\mathrm{RR}_{\mathrm{G}} \mathrm{P}_{\mathrm{B}}\right) .
$$

We knew the proportions of exposed people in the various groups. The individual-level risk ratios could therefore be derived from risk ratios estimated on a group level. With the group-level estimates from step 2, for the occupational groups with a high and low prevalence of prolonged standing, we used equation 2 to estimate the individual-level risk ratio between employees that spent more than $75 \%$ of their workday in a standing position and the rest of the working population. To take the sampling errors into account, we used the propagation-of-error formulas (19) in the formation of the $95 \%$ confidence intervals around the estimated individual-level risk ratios.

\section{Results}

Table 2 (see page 418) shows the standardized hospitalization ratios for varicose veins by occupation for the categories of a high and low proportion of standing. In general we found a consistent pattern for low standardized hospitalization ratios due to hospitalization with varicose veins in occupational groups with a low proportion of standing work. For the men the overall standardized hospitalization ratio in this category was $76(95 \%$ CI 6884). Two job groups had standardized hospitalization ratios above 100 , but none of the 12 occupational groups had a statistically significant high risk. For male occupations with a high proportion of standing the overall standardized hospitalization ratio was 137 (95\% CI 123 - 153). Three job groups had standardized hospitalization ratios below 100 , but none of these groups had a significantly low risk. For women we found the same consistent pattern of low risk in occupations with a low proportion of standing at work (SHR 54, 95\% CI 5059) and a high risk (SHR 143, 95\% CI 136-150) for occupations with a high proportion of standing at work.

Figure 1 (see page 419) presents the age-standardized hospitalization ratios for the occupational groups stratified according to the proportion of standing and the proportion of smokers. Again, a consistent pattern of increasing risk of varicose veins with an increasing proportion of standing at work.

The results from the group-level Poisson regression, in which all the variables were handled simultaneously, are given in table 3 (see page 419).

From equation 2, the extracted age, social group, and smoking standardized risk ratios for varicose veins among people who stand more than $75 \%$ of their workshift compared with the other employees was $1.85(95 \%$ CI 1.33-2.36) for the men and 2.63 (95\% CI 2.253.02) for the women.

\section{Discussion}

Surveys based on random population samples, as well as record-linkage studies, have both strengths and weaknesses. Much information on potential confounders is available from surveyed samples, but diseases are often too rare to be studied in such samples. Disease frequencies may be sufficient in record linkage studies based on the entire population, and follow-up periods are often sufficiently long. In this study we used a hybrid approach and combined information from a surveyed subsample with information from record-linkage data on the entire population. This procedure enabled us to analyze the association between standing at work and venous vascular disease prospectively while controlling for age, 
Table 2. Standardized hospitalization ratios (SHR) and 95\% confidence intervals (95\% Cl) for varicose veins in $1991-1993$ by occupation, proportion of standing at work, and proportion of smokers in 1990.

\begin{tabular}{|c|c|c|c|c|c|c|}
\hline Gender & $\begin{array}{l}\text { Proportion } \\
\text { of smokers }\end{array}$ & $\begin{array}{l}\text { People at } \\
\text { risk (N) }\end{array}$ & $\begin{array}{l}\text { Observed } \\
\text { (N) }\end{array}$ & $\begin{array}{l}\text { Expected } \\
\text { (N) }\end{array}$ & SHR & $95 \% \mathrm{Cl}$ \\
\hline \multicolumn{7}{|l|}{ Men } \\
\hline \multicolumn{7}{|l|}{ Low proportion of standing worka } \\
\hline Architect, engineer (4202) & Low & 41080 & 44 & 89.3 & 49 & $36-66$ \\
\hline Agent, retail manager, estate agent (4241) & Low & 8038 & 13 & 20.0 & 65 & $35-111$ \\
\hline Bookkeeper, cashier (4332) & Low & 6901 & 8 & 15.1 & 53 & $23-105$ \\
\hline Programmer (4408) & Low & 3486 & 1 & 5.6 & 18 & $0-99$ \\
\hline Accounts staff, bank clerk (4432) & Low & 5904 & 3 & 7.5 & 40 & $8-116$ \\
\hline Head of administration ( 4220 ) & Medium & 25467 & 42 & 67.7 & 62 & $45-84$ \\
\hline Salesman (4441) & Medium & 25575 & 54 & 42.9 & 126 & $94-164$ \\
\hline Office manager, head clerk, etc (4231) & Medium & 14281 & 11 & 34.0 & 32 & $16-58$ \\
\hline Shop supervisor (4341) & Medium & 16460 & 25 & 35.0 & 71 & $46-106$ \\
\hline Office staff (4431) & High & 40136 & 49 & 59.4 & 82 & $61-109$ \\
\hline Transport staff (4497) & High & 4892 & 9 & 9.9 & 91 & $42-173$ \\
\hline Professional driver (4697) & High & 60196 & 131 & 128.4 & 102 & $85-121$ \\
\hline Total & . & 252416 & 390 & 514.8 & 76 & $68-84$ \\
\hline \multicolumn{7}{|l|}{ High proportion of standing work ${ }^{a}$} \\
\hline Unskilled food industry worker (4677) & Low & 19762 & 58 & 31.5 & 184 & $140-238$ \\
\hline Skilled construction worker (4595) & Medium & 40739 & 86 & 72.0 & 119 & $96-147$ \\
\hline Unskilled wood industry worker (4681) & Medium & 9496 & 52 & 21.7 & 240 & $179-314$ \\
\hline Manufact., rubber and plastic (4690) & Medium & 1983 & 4 & 3.0 & 133 & $36-343$ \\
\hline Fitter, mechanic (4584) & Medium & 34599 & 62 & 67.9 & 91 & $70-117$ \\
\hline Skilled food industry worker (4577) & High & 10637 & 51 & 21.7 & 235 & $175-309$ \\
\hline Painter (4593) & High & 10811 & 20 & 21.2 & 94 & $58-145$ \\
\hline Janitor, cleaner (4652) & High & 6197 & 11 & 10.7 & 103 & $51-184$ \\
\hline Metal worker (4683) & High & 267 & 0 & 0.6 & 0 & $0-586$ \\
\hline Total & . & 134491 & 344 & 250.5 & 137 & $123-153$ \\
\hline \multicolumn{7}{|l|}{ Women } \\
\hline \multicolumn{7}{|l|}{ Low proportion of standing work ${ }^{a}$} \\
\hline Office manager, managing clerk etc (4231) & Low & 9403 & 13 & 43.2 & 30 & $16-52$ \\
\hline Accounts staff, bank clerk (4432) & Low & 18673 & 42 & 79.7 & 53 & $38-71$ \\
\hline Office supervisor (4331) & Medium & 4815 & $\begin{array}{r}42 \\
9\end{array}$ & 26.1 & 34 & $16-66$ \\
\hline Office staff (4431) & Medium & 231770 & 547 & 956.7 & 57 & $52-62$ \\
\hline Head of administration (4220) & Medium & 4057 & 6 & 21.1 & 28 & $11-62$ \\
\hline Book-keeper, cashier (4332) & Medium & 8043 & 16 & 39.4 & 41 & $23-66$ \\
\hline Technician (4403) & Medium & 10926 & 25 & 43.9 & 57 & $37-85$ \\
\hline Electrician's assistant (4685) & High & 416 & 1 & 2.1 & 48 & $1-267$ \\
\hline Total & . & 288103 & 659 & 1212.0 & 54 & $50-59$ \\
\hline \multicolumn{7}{|l|}{ High proportion of standing worka } \\
\hline Shop worker (4641) & Low & 1632 & 9 & 5.3 & 170 & $77-320$ \\
\hline Leading hotel and catering staff (4351) & Medium & 1536 & 11 & 6.5 & $\dagger 69$ & $84-303$ \\
\hline Building administration staff (4452) & Medium & 831 & 6 & 4.3 & 140 & $51-301$ \\
\hline Hotel worker, home help etc (4651) & Medium & 87696 & 619 & 397.5 & 156 & $144-168$ \\
\hline Janitor, cleaner (4652) & Medium & 51494 & 317 & 250.1 & 127 & $113-142$ \\
\hline Hospital staff (4406) & High & 75377 & 475 & 337.4 & 141 & $128-254$ \\
\hline Other hotel and catering staff (4451) & High & 4916 & 21 & 20.1 & 104 & $65-160$ \\
\hline Total & 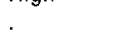 & 223482 & 1458 & 1021.3 & 143 & $136-150$ \\
\hline
\end{tabular}

a Code of the extended classification of the International Standard Classification of Occupations in parentheses.

gender, smoking, and social group. The results showed a consistent pattern of a graded and statistically significant relationship between standing at work and hospitalization with varicose veins for both men and women. Our results point to a strong association between standing and walking at work and the subsequent occurrence of varicose veins.

The validity of this association is, however, based on the assumption that there was no differential misclassification of exposure. We found the risk of differential misclassification very small for the following 3 reasons: (i) the exposure measure was based on the average response in job groups, not on the responses of individual persons, (ii) the evaluation of the standing and walking workhours was performed by a healthy group of workers, most of whom had not been and never will be hospitalized for varicose veins; and (iii) the information on standing and walking at work is very unlikely to be influenced by attitudes or general health status since this is a rather matter-of-fact piece of information. Therefore, we have no reason to believe that the association found was due to a differential misclassification of exposure.

However, a higher inclination to seek hospital treatment among workers standing at work cannot be ruled out. In such a case our result would involve slight overestimation because we had no possibility to exclude these 
people from the study base. We cannot rule out the possibility that people of higher socioeconomic status are more likely to seek help in private clinics outside the hospital system. If so, we may have overestimated the risk. On the other hand, we have adjusted for social group. This adjustment is likely to have resulted in overadjustment because both the amount of standing at work and socioeconomic status are determined by occupational group (20). We used hospitalizations as a proxy measure for the underlying incidence of varicose veins. Studies using hospitalization as the end point are often associated with referral or admission bias arising from social and geographic differences in the tendency to consult hospitals for medical care $(21-22)$. All health care in Denmark is, however, free of charge and a hospital can be promptly reached by any citizen. It was earlier shown for ischemic heart disease that lower-grade hospital staff was the only occupational group that was subject to referral bias (21), and we expect the same to be true for varicose veins. It is known that circulatory diseases cause strong migration from heavy work to light work and out of work. For more severe varicose veins this selection effect may also be strong. Our 1-year assessment of the occupation before the baseline of the 3-year follow-up may have reduced this selection considerably, but some remaining healthy worker effect may have biased our results towards unity.

The biological basis for the standing hypothesis is the impeded blood flow and consecutive stasis in veins of the lower extremities because of increased intravascular hydrostatic pressure in an upright work position. Stasis in the venous system is a key mechanism in venous vascular disease. Stasis increases the risk for coagulation and thrombus formation. The same mechanisms operate during walking, but probably to a less degree because the activation of the leg muscle pump during walking may reduce the venous stasis associated with an upright position as long as the venous valves are intact. Once the venous valves are incompetent, walking may actually increase venous pressure in the lower extremities because of a reversal in blood flow.

Studies designed to identify dose-response relations and threshold limits should be carried out. These studies should also include other disease outcomes associated with prolonged standing, such as low-back pain (23) and arterial cardiovascular outcomes $(24-25)$. The followup of men with varicose veins in the Framingham study indicated that varicose veins may be a risk factor for intermittent claudication and, at least in the lower social class, for coronary heart disease (24). A recent prospective Finish study showed that rapid progression in carotid atherosclerosis was predicted by prolonged standing at work, and the hypothesis was raised that hemodynamic changes associated with standing at work may play a role in both venous and arterial vascular disease (25).

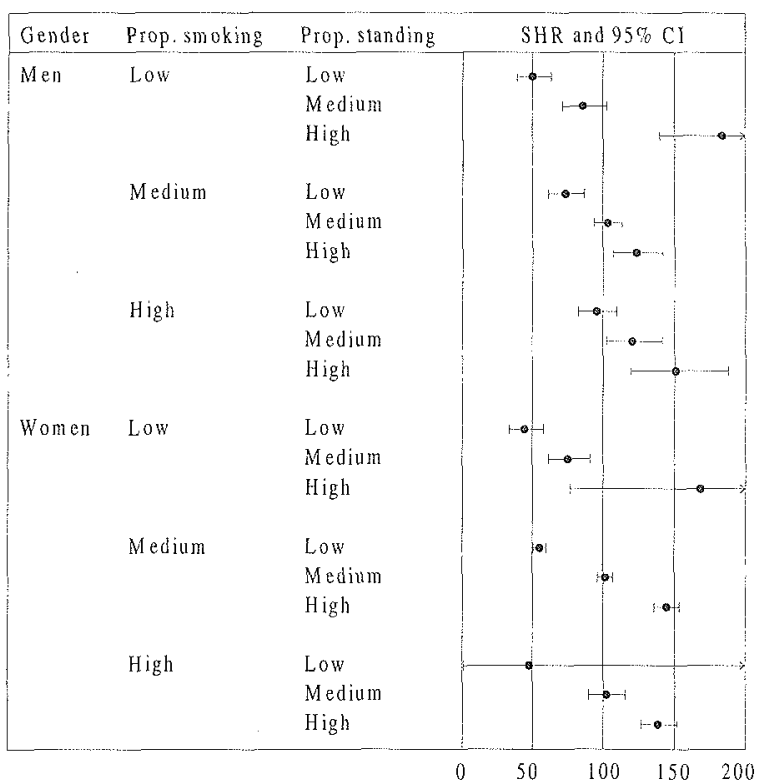

Figure 1. Standardized hospitalization ratios (SHR) and $95 \%$ confidence intervals for varicose veins by proportion of standing at work and proportion of smokers. Danish men and women aged 20-59 years in 1991 and followed for 3 years.

Table 3. Age-standardized risk ratios (RR) and $95 \%$ confidence intervals $(95 \% \mathrm{Cl})$ for varicose veins, obtained by Poisson regression with simultaneous adjustment for the proportion of standing at work, proportion of smokers, and social group.

\begin{tabular}{|c|c|c|}
\hline & Men & Women \\
\hline & $\begin{array}{l}\text { Ad- } \\
\text { justed } \\
\text { RR }\end{array}$ & $\begin{array}{l}\text { Ad- } \\
\text { justed } \\
\text { RR }\end{array}$ \\
\hline \multicolumn{3}{|l|}{$\begin{array}{l}\text { Proportion of workers standing } \\
\text { at work }\end{array}$} \\
\hline Low (men $17 \%^{a}$, women $2.7 \%^{a}$ ) & 1.00 & 1.00 \\
\hline $\begin{array}{l}\text { Medium (men } 63 \%^{\mathrm{a}} \text {, women } \\
54 \%^{\mathrm{a}} \text { ) } \\
\text { High (men } 95 \%^{\mathrm{a}} \text {, women } 85 \%^{\mathrm{a}} \text { ) }\end{array}$ & $\begin{array}{l}1.251 .08-1.44 \\
1.581 .30-1.91\end{array}$ & $\begin{array}{l}1.971 .75-2.21 \\
2.292 .02-2.60\end{array}$ \\
\hline \multicolumn{3}{|l|}{ Proportion of smokers } \\
\hline $\begin{array}{l}\text { Low (men } 56 \%^{\mathrm{b}} \text {, women } 50 \%^{\mathrm{b}} \text { ) } \\
\text { Medium (men } 68 \%^{\mathrm{b}} \text {, women }\end{array}$ & 1.00 & 1.00 \\
\hline $\begin{array}{l}\left.59 \%^{b}\right) \\
\text { High (men } 80 \%^{b} \text {, women } 71 \%^{\mathrm{b}} \text { ) }\end{array}$ & $\begin{array}{l}1.040 .89-1.22 \\
1.08 \quad 0.89-1.32\end{array}$ & $\begin{array}{l}1.221 .04-1.44 \\
1.180 .98-1.42\end{array}$ \\
\hline \multicolumn{3}{|l|}{ Social group } \\
\hline Senior salaried staff & 1.00 & 1.00 \\
\hline Other salaried staff & $1.461 .17-1.83$ & $2.291 .70-3.09$ \\
\hline Skilled workers & $1.511 .19-1.91$ & \\
\hline Unskilled workers & $1.741 .35-2.25$ & $2.621 .95-3.53$ \\
\hline
\end{tabular}

a Proportion in the quartile who stands or walks more than $75 \%$ of the time.

- Proportion in the quartile who has ever smoked.

In conclusion, we found that working in a standing position or walking was associated with subsequent hospitalization due to varicose veins for both men and women. 


\section{Acknowledgments}

The our study was supported by the Danish Health Insurance Fund, grant 11/108-99, and by grant HL07365 from the National Heart, Lung, and Blood Institute, United States.

\section{References}

1. Tüchsen F, Bach E. Erhverv og hospitalsindlæggelse 1981 1984 [Occupation and hospitalization 1981-1984]. Copenhagen: Arbejdsmiljøfondet, 1992.

2. Callum MJ, Epidemiology of varicose veins. Br J Surg 1994; 81:167-73.

3. Sisto T, Reunanen A, Laurikka J, Impivaara O, Heliövaara M, Knekt P, Aromaa A. Prevalence and risk factors of varicose veins in lower extremities: mini-Finland health survey. Eur J Surg 1995;161:405-14.

4. Hobson J. Venous insufficiency at work. Angiology 1997; 48:577-82.

5. Evans CJ, Fowkes FGR, Ruckley CV, Lee AJ. Prevalence of varicose veins and chronic venous insufficiency in men and women of the general population: Edinburg Vein Study. J Epidemiol Community Health 1999;53;149-53.

6. Brand FN, Dannenberg AL, Abbott RD, Kannel WB. The epidemiology of varicose veins: the Framingham study. Am J Prev Med 1988;4:96-101.

7. Barnes RW. Vascular holism: the epidemiology of vascular disease. Ann Vasc Surg 1995;9:576—82.

8. Stvrtinova V, Kolesar J, Wimmer G. Prevalence of varicose veins of the lower limbs in the women working at a department store. Int Angiol 1991;10:2-5.

9. Weddell JM. Varicose veins pilot survey, 1966. Br J Prev Soc Med 1969;23:179-86.

10. Pirnat L. Systematic studies of the varicose symptom complex in industry. Zentralbl Phlebol 1967;6:265-75.

11. Mekky S, Schilling RS, Walford J. Varicose veins in women cotton workers: an epidemiological study in England and Egypt. BMJ 1969;2:591-5.

12. Abramson JH, Hopp C, Epstein LM. The epidemiology of varicose veins: a survey in western Jerusalem. J Epidemiol Community Health 1981;35:213-7.
13. Lorenzi G, Bavera L, Cipolat L, Carlesi R. The prevalence of primary varicose veins among workers of a metal and steel factory. In: Negus D, Jantet G, editors. The prevalence of primary varicose veins among workers of a metal and steel factory. London, Paris: John Libbey, 1985.

14. Guberan E, Widmer LK, Glaus L, Muller R, Rougemont A, Da Silva A, et al. Causative factors of varicose veins: myths and facts: an epidemiological study of 610 women. Vasa $1973 ; 2: 115-20$.

15. Maffei FH, Magaldi C, Pinho SZ, Lastoria S, Pinho W, Yoshida WB, et al. Varicose veins and chronic venous insufficiency in Brazil: prevalence among 1755 inhabitants of a country town. Int J Epidemiol 1986;15:210-17.

16. Borg V, Kristensen TS, Burr H. Work environment and changes in self-rated health: a five year follow-up study. Stress Med 2000;16:37-47.

17. Bach E. Validering af EIR - et arbejdsepidemiologisk moniteringssystem [Validation of the Occupational Hospitalization Register - an occupational health surveillance system] [dissertation]. Copenhagen: University of Roskilde and $\mathrm{Na}$ tional Institute of Occupational Health, 1998.

18. Tüchsen F, Jeppesen HJ, Bach E. Employment status, nondaytime work and gastric ulcer in men. Int $\mathrm{J}$ Epidemiol 1993;23:365-70.

19. Ku HH. Notes on the use of the propagation of error formulas. J Res Natl Bur Stand 1966;70C:263-73.

20. Brisson C, Loomis D, Pearce N. Is social class standardization appropriate in occupational studies? J Epidemiol Community Health 1987;41:290-4.

21. Tüchsen F, Andersen O, Olsen J. Referral bias among health workers in studies using hospitalization as a proxy measure of the underlying incidence rate. J Clin Epidemiol 1996; 49:791-4.

22. Sackett DL. Bias in analytical research. J Chronic Dis 1979;32;51-63.

23. Magora A. Investigation of the relation between low back pain and occupation. Ind Med Surg 1970;39:465-71.

24. Ducimetiere P, Richard JL, Pequignot G, Warnet JM. Varicose veins: a risk factor for atherosclerotic disease in middleaged men? Int J Epidemiol 1981;10:329-35.

25. Krause N, Lynch J, Kaplan GA, Cohen R, Salonen R, Salonen JT. Standing at work and progression of carotid atherosclerosis. Scand J Work Environ Health 2000;26(3):227-36.

Received for publication: 20 September 1999 